\title{
ERRATA
}

\section{Toxicity Studies of Metabolites of Some Fungal Isolates in Albino Mice}

BHARATI PATHAK, N. SETHI, JOYOTI GUPTA, AND V. C. VORA

Division of Fermentation Technology and Division of Experimental Medicine, Central Drug Research Institute, Lucknow, India

Volume 46, no. 4, page 944, column 1, paragraph 1, line 5: "Gupta et al. (3) and Itakura and Kinosita (7)" should read "Gupta et al. (3), Itakura and Kinosita (7), Thacker et al. (12), and Zimmerman et al. (15)."

Page 944, column 1, paragraph 3, line 3: “. . . as reported earlier $(3,7)$ " should read ". . . as reported earlier $(3,9)$." Page 944, column 2, paragraph 1, lines 4 and 7: Reference 10 should be reference 13.

Pages 946-947, Literature Cited: The following references should be deleted: numbers 5, 8, 10, and 11 .

\section{Purification and Characterization of Extracellular Proteinases of Aspergillus oryzae}

\author{
A. K. KUNDU AND S. MANNA \\ Department of Microbiology, East India Pharmaceutical Works Ltd., Calcutta-60, India
}

Volume 30 , no. 4 , p. 507-513: Proteolytic activities throughout should be multiplied by 3.2 to express correct units. 